\title{
THE INFLUENCE OF CRIMINAL OFFENDING ON UNION FORMATION AND UNION DISSOLUTION FOR DISADVANTAGED INDIVIDUALS
}

M. Zoutewelle-Terovan, V. van der Geest, A. C. Liefbroer, C. Bijleveld

Mioara Zoutewelle-Terovan (responsible for correspondence), Dr., Researcher VU University Amsterdam, Faculty of Law

Email: zoutewelle@nidi.nl

Victor van der Geest, Dr., Researcher

VU University Amsterdam, Faculty of Law

Email: VvanderGeest@nscr.nl

Aart Cornelis Liefbroer, Prof. Dr., Senior Researcher

VU University Amsterdam, Faculty of Social Sciences

Netherlands Interdisciplinary Demographic Institute (NIDI)

Email: liefbroer@nidi.nl

Catrien Bijleveld, Prof. Dr. LLM, Senior Researcher

The Netherlands Institute for the Study of Crime and Law Enforcement (NSCR)

VU University Amsterdam, Faculty of Law

Email: Cbijleveld@nscr.nl 


\title{
THE INFLUENCE OF CRIMINAL OFFENDING ON UNION FORMATION AND UNION DISSOLUTION FOR DISADVANTAGED INDIVIDUALS
}

\begin{abstract}
Using a sample of 248 males and females from the Netherlands, we study the effect of criminal offending on union formation and union dissolution. Criminal and relational careers of high-risk respondents are analyzed using a long observation period (age 12 to age 36). Findings for men support the hypothesis that past criminal offending reduces the likelihood of being involved in a romantic relationship. Furthermore, male's past violent offending increases the probability of being single. Analysis of union dissolution for males showed that only recent violent offending is associated with the termination of a romantic relationship. Similar to our findings for men, findings for females show that the likelihood of being involved in a romantic relationship is negatively associated with past criminal offending. Moreover, it is an extended cumulative history of property offenses that significantly increases the likelihood of being single throughout the observation period. For women, recent offending significantly increases the probability of separation/divorce.
\end{abstract}

Key words: life-course, gender differences, romantic relationships, romantic dissolution, offending, violent, property

\section{INTRODUCTION}

An extensive body of research has focused on the effect of romantic relationships (marriage in particular) on offending for both males and females (Farrington and West 1995; Osgood, and Marshall 1995; Sampson, Laub, and Wimer 2006; King, Massoglia, and MacMillan 2007; Bersani, Laub, and Nieuwbeerta 2009; Zoutewelle-Terovan et al. 2012; Jaffee, Lombardy, and Coley 2013). However, considerably less attention has been paid to the opposite relationship, namely the effect of criminal behavior on romantic relationships. Moreover, the existing research that investigated this opposite direction paid relatively little attention to some potentially relevant aspects.

First, the majority of existing studies analyzed the effect of incarceration rather than the effect of offending on the likelihood of marriage and divorce. Often, incarceration studies have been criticized for observing a selective group of individuals, namely persons who commit most serious offenses, have extended criminal histories (Apel et al. 2010), and are 
physically separated from (prospective) romantic partners. However, what such studies did not address is the fact that antisocial behavior (not necessarily associated with incarceration) might by itself significantly influence the development of romantic life (van Schellen, Poortman, and Nieuwbeerta 2011; Jaffee, Lombardy, and Coley 2013). This is of particular interest in countries such as the Netherlands (the country where our study was conducted), known for a liberal penal climate, with low incarceration rates and short incarceration periods.

Second, studies investigating the effects of criminal behavior on romantic relationships predominantly concentrated on marriage. This was only a minor limitation for older cohorts, where marriage was the dominant form of intimate relationship (van Schellen, Poortman, and Nieuwbeerta 2011; Sampson, Laub, and Wimer 2006). Among more recent cohorts, family life trends have become less standardized (Elzinga and Liefbroer 2007) and non-marital unions (especially cohabitation) have become the norm rather than the exception in many countries. Furthermore, to a notable extent, previous research has analyzed the probability and timing of first marriage (respectively first divorce). In modern societies, with individuals often experiencing multiple and sequential unions during adolescent and adult life, life-course research should devote considerable attention to the influence of offending on multiple romantic involvements.

Third, much of the existing literature centered on the effect of a cumulative number of offenses on union formation. To date, few studies have analyzed different types of offenses (King and South 2011). It is envisageable that some kinds of offenses (notably violent offenses) jeopardize relationships more than others. Previous literature has been limited in providing answers on whether various types of offenses encompass unique characteristics or reflect different expressions of the same underlying criminal propensity.

Fourth, previous research has mainly focused on male offenders. Studying female offenders was often problematic given the low rate of offending among this group (Huebner 2005; Apel et al. 2010; Jaffee, Lombardy, and Coley 2013). However, it is important to extend research to female offenders and provide answers to questions about gender specificities.

Given this situation, the aim of this study is to investigate the influence of criminal behavior on union formation and union dissolution. Using a high-risk sample of males and females in the Netherlands, the current study will be guided by the following research questions:

1) Does offending negatively influence the likelihood of being involved in a romantic relationship? 
2) Is the effect of offending on intimate relationships different for different types of unions (any relationship or a living-together relationship)?

3) Does offending positively influence the likelihood of separation from a romantic partner?

4) Do different types of offenses (violent, property) have a similar effect on the likelihood of being involved in an intimate relationship or terminating an existing one?

5) Are there gender differences in any of the above?

\section{BACKGROUND AND HYPOTHESES}

\subsection{Criminal behavior and union formation}

Symbolic interactionism offers one account of the potential effects of criminal behavior on union formation. Labeling theorists argue that criminal behavior negatively influences various life events (Lemert 1967; Paternoster and Iovanni 1989), and romantic prospects are diminished through the stigma attached to an offender. A 'criminal status' might define an individual as immature, unreliable, untrustworthy, connected to criminally involved peers, and prone to reoffend (Gottfredson and Hirschi 1990; Lopoo and Western 2005). Furthermore, after engaging in initial criminal behavior (primary deviance), an individual might change his self-concept and internalize a deviant identity (Lemert 1967). As individuals commit to a criminal life-style (secondary deviance), the negative consequences of stigma perpetuate and cumulate throughout adult life, limiting one's opportunities for romantic involvement.

Much of the current knowledge about the mechanisms explaining the effect of a criminal record on romantic relationships results from research focusing on the consequences of incarceration on marital unions. A great deal of evidence supports the idea that recent incarceration reduces short-term probability of marriage (Huebner 2005; Sampson, Laub, and Wimer 2006). Less consensus exists regarding the long-term effects of incarceration on marriage. Some studies provide support for the hypothesis that prior incarceration reduces the probability of marriage (Sampson, Laub, and Wimer 2006; Huebner 2007). Other studies do not report long-term effects of incarceration on marriage (Lopoo and Western 2005; Apel et al. 2010). For females, the long-term effects of incarceration on marriage remain unclear given that all studies previously mentioned analyzed male respondents only. 
The impact of criminal behavior on the probability of marriage received considerably less attention. Using a conviction sample, van Schellen, Poortman, and Nieuwbeerta (2011) found that, compared to non-offenders, the likelihood of marriage was reduced by $24 \%$ for offenders committing more than six offenses until the previous year, and by $42 \%$ for men who committed more than 10 offenses. Men who committed fewer offenses did not differ in their likelihood of marriage compared to non-offenders. In their analysis, the effect of a criminal record diminished over time. A different study conducted by Sampson, Laub, and Wimer (2006) found that male juvenile delinquent behavior was negatively associated with the likelihood of marriage. Similarly, a study of twins revealed that men with lower levels of antisocial behavior are more likely to marry (Burt et al. 2010). Yet, the study of Barnes et al. (2011) found no significant effect of criminal behavior on marriage. Similar to the incarceration studies, research on criminal behavior has focused predominantly on men.

More recent studies examined romantic relationships (other than marriage) as an outcome. Similar to the marriage studies, there is no general agreement regarding the effects of criminal behavior/incarceration on union formation. Western, Lopoo, and McLanahan (2004) analyzed parents of new born children, and found that men with incarceration records were $19 \%$ less likely to be cohabiting (and 37\% less likely to be married) in the year their child was born (compared to never-incarcerated males). In a study investigating the reciprocal relationship between cohabitation and offending for students, Lonardo et al. (2010) found that delinquent behavior was associated with 2.6 higher odds of cohabitation. They also concluded that females had higher probabilities to experience cohabitation compared to males. In contrast to these findings, London and Parker (2009) found that incarcerated individuals were about three times more likely to cohabit than non-incarcerated individuals. Moreover, Rebellon and Manasse (2004) concluded that men with more delinquent activity were associated with more extended romantic activity.

Starting from these considerations, the following hypotheses were formulated: H1 - Offending increases the likelihood of being without a romantic partner (being single). H2 - Offending decreases the likelihood of being involved in a living-together relationship (cohabitation and marriage versus singlehood or non-cohabitation).

\subsection{Types of offenses and union formation}

Existing theories have not extensively discussed whether specific types of offenses (e.g. violent, property) differ in their influence on intimate relationships. Furthermore, the effect of various types of offenses on union formation has rarely been empirically tested. 
Studies analyzing the influence of violent offending on romantic relationships provided mixed results. Focusing on marital unions, Sampson, Laub, and Wimer (2006) found that a history of violent offending reduced the likelihood of marriage for males. Other studies found no significant relation between violent crime and marriage (Lopoo and Western 2005; van Schellen, Poortman, and Nieuwbeerta 2011). A particular group of studies focused on domestic violence and its association with romantic relationships. Western (2006) found that fathers of new-born children were more likely to be aggressive towards the mothers of their children if they had a prison record. Silverman et al. (2001) concluded that being in a relationship increased the risk for physical and sexual violence among female students. Edin and Kefalas (2005) showed that for poor females the fear of becoming a victim of domestic violence inhibited them from entering marital unions. Overall, individuals raised concerns about their safety (or the safety of other significant ones) when contemplating a relationship with a violent partner, resulting in avoidance of romantic relationships with such individuals.

The influence of property offending on romantic choices is less clear-cut, and depends on the evaluation of the economic dimension of property offending. On the one hand, property offenders could be viewed as individuals who are less able to provide for a family (Buikhuisen and Dijksterhuis 1971; Pager 2003). In addition, the increased participation of females on the labor market in modern times might lead to an increased value of economic participation of the prospective partner on the marriage/mating market. In a recent study, King and South (2011) concluded that involvement in property offending was connected with employment instability or unemployment; therefore individuals were seen as less attractive romantic partners. On the other hand, the opposite effect is also possible: within groups where offending is not considered deviant, property offending could be seen as a source of income that increases one's value on the mating market. Such an effect is in line with Becker's theoretical concepts on family economics (Becker 1993), stating that individuals seek partners with potential to maximize existing well-being. As a result, offenders with economic prospects might be seen as more attractive mating candidates.

Based on these considerations, we formulate the following hypotheses:

H3 - Violent offending decreases the likelihood of being in a relationship.

H4 - Property offending increases the likelihood of being in a relationship.

\subsection{Criminal behavior and union dissolution}

Stigma theorists suggest that a criminally labeled individual does not only have limited access to potential partners, but that the social consequences of criminal behavior (rejection 
by peers, limited economic perspectives) might also increase the risk of separation/divorce for those involved in a romantic relationship (Paternoster and Iovanni 1989; Lemert 1967). Research on the effects of criminal behavior on union dissolution was even more rare than research on union formation, and mostly focused on the influence of incarceration on divorce among males. To a large extent, the divorce literature states that incarceration increases the likelihood of divorce in both the short term and the long term. Lopoo and Western (2005) found that incarcerated individuals had a higher probability of divorce than the nonincarcerated. Similarly, Apel et al. (2010) found that imprisonment was associated with a higher likelihood of divorce in the years after release, and that this effect increased over time. Focusing on long-term effects of juvenile incarceration, Sampson and Laub (1993) reported that juvenile confinement increased the likelihood of divorce in both young (ages 17-25) and middle (ages 25-32) adulthood. Interestingly, in their study incarceration before entering marriage did not significantly influence men's transition to divorce. Other studies analyzed non-marital relationships as well. Western and McLanahan (2000) found that a cumulated history of incarceration of the father reduced the odds of living with the child's mother (in marriage or cohabitation) by $49 \%$. Although empirical research on females is rare, studies focusing on antisocial girls (see Pajer 1998 for a review) concluded that they experienced less marital satisfaction and a higher likelihood of divorce.

Several studies suggested that the risk of divorce depended on the nature of offending. Apel et al. (2010) found that men incarcerated for more severe offenses were at higher risk of divorce than men imprisoned for a less serious offense. Lopoo and Western (2005) found that illegal income in the past did not relate to the likelihood of divorce, but aggravated assault in the past increased the chances of divorce by $35 \%$.

Based on these considerations, the following hypotheses were formulated:

H5 - Offending increases the likelihood of separation/divorce.

H6 - Violent offending increases the likelihood of separation/divorce.

\subsection{Gender differences}

Most theories on the effects of criminal behavior on union formation/dissolution do not explicitly discuss whether effects differ between men and women. Nevertheless, some inferences on gender differences can be made from that literature.

Given that men constitute a larger pool of offenders, Sampson, Laub and Wimer (2006) concluded that delinquent men marry "up" and delinquent women marry "down". In the context of mating competition, females with few relevant resources on the marriage 
market could become more tolerant towards a criminal record of a potential partner (negative labeling effects are less strong for males). Females' higher tolerance towards criminal behavior of their partner might also be explained in the context of feminist theories. As female offenders are considered to embrace more traditional feminine values (Curran and Renzetti 2001), a potential partner might be seen as attractive if he is willing to assume the economic responsibility of being the main bread-winner (even through criminal activities).

There could also be gendered effects of criminal behavior on union dissolution, especially in the context of intimate partner violence. In a review of 20 studies focusing on females, Pajer (1998) concluded that the adult life of antisocial girls was associated with increased chances of victimization. Tjaden and Thoennes (2000) found that married/cohabiting females were significantly more exposed to partner-perpetrated rape, physical assault, and stalking than males. Their victimization experiences were also more frequent and longer lasting. If females are socialized to be more dependent, passive, obedient and focused on the harmony of the relationship than males (Curran and Renzetti 2001; Moffit et al. 2001), they might also be less likely than males to view the criminal behavior of their partner (even if this threatens ones safety) as a sufficient reason for separation/divorce.

\section{UNION FORMATION IN THE NETHERLANDS}

Recent demographic changes in Western societies point to the deinstitutionalization of marriage and institutionalization of alternative unions (Cherlin 2004). Young adults are more likely to cohabit before marriage and even to replace marriage by cohabitation (Hiekel 2014). In the Netherlands, the social meaning of marriage and cohabitation changed as well. Starting as a "deviant" form of union in the 1970s (Manting 1996), cohabitation became increasingly popular during the following decades. In 1980, only $60 \%$ of the population approved of cohabitation as a trial period preceding marriage, while social acceptance increased over time, reaching 85\% in 1991 (Manting 1996). The acceptance of cohabitation without the intention to marry increased as well: from $41 \%$ in 1980 to $71 \%$ in 1991 (Manting 1996). In 1998, the Netherlands introduced the possibility to formally register a cohabiting union. The legal benefits of a registered partnership are virtually identical to the ones of marriage (the exception being parental rights of children born within a registered partnership), but the termination of a registered partnership takes less administrative steps and does not require a court decision. According to Statistics Netherlands, registered partnerships represent about 
$10 \%$ of the yearly registered unions (CBS 2011). Nevertheless, a considerable number of couples cohabit without an official registration.

According to Kiernan (2004), one in four unions in the Netherlands is a registered or non-registered cohabitation. Compared to other European countries, the Netherlands occupy a middle position. Sweden holds the top position with cohabitations representing about $50 \%$ of all formed unions, whereas in Greece only one in twelve unions is a cohabitation.

In the context of increased cohabitation rates among the Dutch population, we would expect this type of union formation to be central among high-risk individuals who are less prone to long-term commitments and who want to avoid the legal implications of marriage.

\section{METHOD}

\subsection{Data and measures}

The analyses use data from the 17Up longitudinal study (Bijleveld, van der Geest and Hendriks 2012) which follows a sample of 540 high-risk individuals (270 males, 270 females) born in the early 1970s. Respondents were treated in their youth in a juvenile treatment center in the Netherlands for severe behavioral problems and/or delinquency. Both boys and girls were on average age 15 when they entered the institution and were treated for an average of 1.5 years. Between 2010 and 2012 individuals were asked to participate in an interview. From the original sample, 41 individuals could not be contacted for different reasons (such as death, emigration, or other reasons). Among those who could be contacted $(N=499)$ we interviewed 251 individuals. For three individuals we obtained incomplete interview information. Thus, for the current study ${ }^{1}$ we used complete data from 248 persons (116 males, 132 females). A response analysis showed that, with the exception of an underrepresentation of homeless respondents, no significant differences between those who participated in the interviews and those who did not participate were observed in terms of criminal behavior, marriage or individual and background characteristics.

During the interviews, a life history calendar was used to obtain retrospective information on romantic relationships. The calendar helped organizing recall based on the relative importance of events (Roberts and Horney 2010), and provided visual cues that helped to reconstruct events and circumstances over the life course. Most people can

\footnotetext{
${ }^{1}$ Formal consent for the study was obtained from the Ministry of Justice and the CERCO ethical committee.
} 
accurately reproduce the timing of important life events, such as marriage, birth of a child, or the death of a relative. These events can act as a reference for allocating other events or transitions on their biographical timeline. We collected yearly information on whether individuals were involved in a romantic relationship, on the type of relationship (noncohabitation union lasting longer than 3 month, cohabitation, or marriage), and on the development of each specific relationship (changed to a different type or terminated). Two dependent variables were constructed for the main analysis. The variable any relationship received a value of 1 for each year in which an individual was involved in a romantic relationship (non-cohabitation, cohabitation and marriage) and a value of 0 otherwise. Given that the small number of marital unions did not allow for a separate analysis of marriage and cohabitation, both types of unions were collapsed into a single category. The variable livingtogether relationship recorded a value of 1 for all individuals sharing a common household and 0 otherwise. The termination of a romantic union was also analyzed. Two dependent variables were constructed for all individuals involved in an intimate relationship. The variable separation any relationship received a value of 1 for every year a romantic relationship terminated and 0 otherwise. Similarly, the variable separation living-together relationship received a value of 1 for each year when a respondent stopped living with a partner, and 0 if they continued to be involved in the relationship.

Information on criminal careers of the respondents was available from the Judicial Documentation abstracts (comparable with "rap sheets") starting from age 12 (the minimum age of criminal responsibility in the Netherlands). The abstracts contain information on all cases registered by the police at the Public Prosecutor's Office, all offenses and the corresponding verdicts. Offenses followed by an acquittal or a so-called technical dismissal ${ }^{2}$ were not considered for this analysis. Two time-varying variables on the criminal behavior of our respondents were constructed. To analyze the short-term effects of offending on romantic relationships, the variable current offending recorded the number of offenses an individual committed in a specific year. To examine the long-term effects of offending, we constructed a variable recording the cumulated number of offenses until the previous year. Given that scholars suggest that the effect of a criminal past diminishes over time (van Schellen, Poortman, and Nieuwbeerta 2011), we constructed a weighted measure for the variable past offending (past offending year ${ }_{j}=$ number offenses offending year ${ }_{j-1}+0.9 \times$ number offenses year $_{j-2}+0.8 \times$ number offenses year ${ }_{j-3}+0.7 \times$ number offenses year ${ }_{j-4}+0.6 \times$ number offenses

\footnotetext{
2 Technical dismissal $=$ the prosecutor dismisses the case because it is expected to end in acquittal (mostly because of insufficient proof)
} 
year $_{j-5}+0.5 \times$ number offenses cumulated starting with age 12 year $_{j-6}$ ). Convictions were classified into several categories according to the Statistics Netherlands Standard Classification of Offenses. In additional analyses, we focused on violent offenses (sexual offenses, assault, abduction, robbery, extortion, threat, battery, murder and manslaughter) and property offenses (qualified and non-qualified theft, burglary, arson). Analysis of other types of offenses (e.g. danger-setting offenses, drug offenses, offenses of the Firearms Act) is not included given that these types occurred only sporadically. Similar to the general offenses measure, both violent and property offenses were measured by two variables: one reflecting current offenses (current violent and current property), and a second one recording past weighted offending (past violent and past property).

Personal data on a set of psychological and background variables was available from treatment files constructed during institutionalization (for extended information see van der Geest, Blokland, and Bijleveld 2009). Several studies suggested that ethnicity (Lopoo and Western 2005; Lonardo et al. 2010; King and South 2011; Van Schellen, Poortman, and Nieuwbeerta 2011), intelligence (Sampson, Laub, and Wimer 2006), educational attainment (Goldscheider and Waite 1986; Huebner 2005), family size (Sampson, Laub, and Wimer 2006), family disruption (Sampson, Laub, and Wimer 2006; Lonardo et al. 2010), drug use (Lopoo and Western 2005), social skills (Spence 2011), and early sexual experiences (Silverman et al. 2001) might represent confounding factors for the offending-romantic relationship nexus. Ethnicity was recorded corresponding to prevailing Statistics Netherlands definitions as a dichotomous variable registering value of 1 for persons with a Dutch ethnic background. The level of intelligence (IQ) was measured on a five point scale (retarded, below average, average, above average, gifted). When entering the treatment center, each individual's level of education was recorded, and coded as a dichotomous variable (1=low level, reflecting no education, primary school or special education). The variable family size recorded the number of members in the family of origin. The variable parental divorce recorded whether the biological parents of the juveniles had divorced before institutionalization (1=divorced parents). To control for the effects of drug addiction, we constructed a dichotomous variable with a value of 1 for all individuals declaring that they were addicted to drugs prior to institutionalization. A dummy variable based on psychological assessments made by the juvenile treatment center recorded whether individuals lacked social skills in interacting with others (1=insufficient social skills). An additional variable recording the age of first consensual intercourse (age first sex) was constructed using retrospective information obtained during interviews. 


\subsection{Analytical approach}

As information on union status is available for a range of years during young adulthood, a person-year file was constructed with separate information for each age at which a respondent was observed. A multilevel logistic random effects model (Rabe-Hesketh and Skrondal 2008) was used to estimate the effect of current and past offending on (a) the likelihood of being involved in an intimate relationship, and (b) the likelihood of terminating an existing relationship. A considerable advantage of this method is that it allows for the analysis of both within-individual and between-individual variation. In the logistic random effects model, the probability of person $i$ at time point $t$ to have a certain status is calculated as follows:

$$
p_{i t}=\frac{1}{1+\exp \left(-\mu_{t}-\beta x_{i t}-\gamma z_{i}-\alpha_{i}\right)}
$$

where $z_{i}$ is a vector of time-constant variables, $x_{i t}$ is a vector of time-varying variables, $\mu_{t}$ is a subject-specific intercept allowed to vary with time, $\beta$ and $\gamma$ are vectors of estimated coefficients for the predictors, and $\alpha_{i}$ (following a normal distribution with a mean of 0 and variance $\tau^{2}$ ) represents differences between persons that are random over time and not accounted for by the predictors.

To answer our research questions, the analysis proceeded in several steps. First, we estimated the effects of current and past offending on the likelihood of being involved in any romantic relationship. In addition, we distinguished between non-cohabiting unions and unions where individuals share a common household, and estimated the short- and long-term effects of offending on the likelihood of being involved in a living-together relationship. In the next step we repeated the previous two analyses, but estimated the effects of current and past violent and property offending instead of the general measure of offending. Next, for all respondents having a partner, we repeated the analyses and estimated the likelihood of separating from a partner. Again, models estimated the effects of current and past offending, as well as current and past violent and property offending.

To examine gender differences, separate models were fitted for males and females. Next, we estimated the equality of parameters between the two independent equations by means of $z$ statistic as it was described by Brame et al. (1998):

$$
z=\theta_{1}-\theta_{2} / \sqrt{\left(S E \theta_{1}\right)^{2}+\left(S E \theta_{2}\right)^{2}}
$$

where $\theta_{1}$ and $\theta_{2}$ represent the two coefficients to be compared, and $S E \theta_{1}$ and $S E \theta_{2}$ the standard errors of the estimated coefficients. 


\section{RESULTS}

\subsection{Descriptive statistics}

For a better understanding of the characteristics of our sample, descriptive statistics on several individual and background factors are presented in Table 1. More than half of the individuals had a Dutch ethnic background (60\% of the males and $70 \%$ of the females). The families of origin that the individuals came from had on average about four members. More than $60 \%$ of the respondents experienced divorce of the biological parents. When institutionalized, $30 \%$ of the boys and $25 \%$ of the girls had attained a low level of education. A below average level of intelligence was registered for $24 \%$ of the males and $34 \%$ of the females (the rest were average or above average). A considerable proportion of respondents had been judged as having insufficient social skills (68\% of the males and $83 \%$ females). In adolescence, $32 \%$ of the males and $14 \%$ of the females were addicted to drugs. Both men and women had their first sexual experience on average at age 15. Overall, these figures suggest that this sample was strongly disadvantaged during childhood and adolescence.

Table 1 about here

In our sample, respondents' romantic relationships were followed for 16 years on average (starting with age 16). Complete information was obtained for a total of 3948 person years. Males spent $13 \%$ of these person years in non-cohabiting relationships, $27 \%$ in cohabiting unions, and $9 \%$ in marriages. Females spent $20 \%$ of the person years in noncohabiting relationships, $41 \%$ in cohabitations, and $8 \%$ in marriages. Across the entire observation period, both men and women were involved in two relationships on average. Almost all individuals were involved in an intimate relationship at least once (97\% of the males and $98 \%$ of the females). At the end of the observation period, $78 \%$ of the males and $85 \%$ of the females had separated from a partner at least once. When analyzing relationships where partners shared a common household, we observed that $90 \%$ of the females and $87 \%$ of the males were at least once involved in a living-together relationship. Living-together relationships terminated at least once for $63 \%$ of the males and $78 \%$ of the females. For a more detailed understanding of the romantic involvement of both males and females during the entire observation period (ages 16 to 36), we constructed Figure 1 presenting the percentage of individuals having an intimate partner at each age under observation. Overall, relatively more females than males were involved in a romantic relationship (with a single 
exception at age 32). Already at age 18, a large percentage of females were romantically involved (and that percentage remained stable until the end of the observation period). The reduced number of observations for females after age 32 explains the fluctuations towards the end of the observation period. Fewer males commit to a relationship in adolescence and emerging adulthood. Percentages for males remained more stable after age 24 when about half of the males were romantically involved.

Figure 1 about here

During the entire observation period of criminal careers (starting with age 12), 95\% of the males and $75 \%$ of the females committed at least one offense. Among offenders, the average number of offenses was 20 for males and 6 for females. Violent offenses were committed by $63 \%$ of the males and $33 \%$ of the females. Among violent offenders, the average number of violent offenses was 5 for males and 2 for females. Property offenses were committed by $87 \%$ of the males and $53 \%$ of the females. Male property offenders committed on average 11 property offenses, while females only 4 . The percentages of males and females committing at least one offence at each specific age are presented in Figure 2. At all ages, a larger number of males committed offenses. Nevertheless, the prevalence of offending decreased by age for both males and females. An interesting drop in offending was observed for females at ages 19-20. This decrease in the percentage of female offenders could be associated with the entrance into parenthood (which is a very common occurrence at this age within our sample).

Figure 2 about here

\subsection{Effects of offending on romantic relationships}

Our analysis first focused on the short-term and long-term effects of offending (general measure) on the likelihood of being involved in an intimate relationship. Results are presented in Models M1 to M4 in Table 2. These models did not identify any significant effects of current offending on having an intimate relationship (any or a living-together relationship) for neither males nor females. An additional direct test of gender differences in the effect of current offending showed no significant difference $(z=1.34)$. Thus, our first two hypotheses were not confirmed as far as short-term effects are concerned. Nonetheless, $\mathrm{HI}$ and $H 2$ were confirmed for long-term effects of criminal behavior on having an intimate 
partner. Past offending significantly influenced the likelihood of having a relationship. For males, with every offense committed, the probability of being involved in any relationship diminished by $3 \%$, and the probability of being involved in a living-together relationship by $4 \%$. For females, each additional offense committed in the past diminished the probability to have a relationship by $11 \%$, and the probability to have a living-together relationship by $7 \%$. Our additional test for gender differences showed that past offending had a stronger influence for females compared to males for all relationships $(z=2.53, p<.05)$, whereas the influence of past offending on living-together relationships did not differ significantly for males and females $(z=0.95)$.

In a second step, the analysis focused on the effects of offending on the likelihood of terminating an intimate relationship. Models M5 to M8 in Table 2 showed that past offending did not significantly influence the likelihood of separation for either males or females (H5 not confirmed). In addition, the $z$ statistics for the difference in coefficients for males and females were not statistically significant $(z=0.45$ for any relationship; $z=1.11$ for living-together relationships). In contrast, current offending was significantly associated with separation (H5 confirmed), but only for females: with every offense committed the probability to terminate any relationship increased by $21 \%$, and the probability to terminate a living-together relationship by $37 \%$. A further analysis of gender differences revealed that the coefficients for males and females did not differ significantly. However, the $z$ values were only marginally non-significant ( $z=-1.86$ for living-together relationships; $z=-1.32$ for any relationship).

We briefly discuss the effects of the additional individual and background factors that were included in Table 2, on the likelihood of having a relationship, and on the likelihood of terminating an existing relationship. For males, none of the considered factors significantly influenced the likelihood of being involved in a relationship or of terminating an existing one. For females, a larger family of origin was associated with a higher probability to be involved in any relationship, and a lower probability to terminate a living-together relationship. A lack of social skills was associated with lower likelihood of relationship termination (any relationship) for females. Addiction to drugs for females was associated with a higher likelihood of terminating any relationship. Last but not least, for females, earlier sexual experiences were associated with significantly lower probabilities to be involved in a relationship.

Table 2 about here 
We next paid attention to the question whether union formation and dissolution were related to specific types of offenses, most notably violent and property offences. Results are presented in Table 3. For males, results revealed that current violent offending led to a $28 \%$ reduction in the likelihood of being involved in a relationship of any type (M9) but had no significant effect on the likelihood of being involved in living-together relationships (M11). Thus, $H 3$ was not confirmed for short-term effects of offending on the likelihood of being single for men. For females, current violent offending remained unrelated to having a romantic partner (M10 and M12). Further statistical testing showed no significant difference between males and females $(z=1.65$ for any relationship; $\mathrm{z}=0.26$ for living-together relationships). When long-term effects of violent offending on romantic involvement were analyzed, we did find confirmation for $H 3$. Males' past violent offending was associated with a significantly lower likelihood of having any partner and of living together with a partner (15\% lower compared to being single or in a non-cohabiting relationship). For females, past violent offending did not influence the likelihood of having a romantic partner (M10 and M12). Further testing of gender differences showed that the coefficients did not differ significantly between males and females $(z=-1.43$ for any relationship; $z=-0.70$ for livingtogether relationships).

When analyzing property offending we separated again between current and past. Current property offenses had no significant influence on having a relationship for neither males nor females, and no significant differences between men and women were revealed by means of $z$ statistic. Cumulated past property offending was related to a lower probability to have any partner, but solely for females (14\% lower compared to being single), and the result differed statistically from the one for males $(z=2.28, p<.05)$. Overall, these results provide little support for $H 4$ associating property offending with an increased likelihood of having a romantic partner.

The termination of a romantic relationship and its association with violent and property offending was analyzed as well. For males, only current violent offending significantly increased the likelihood of separation from any relationship by 46\% (M13), whereas for females the $42 \%$ increase was marginally non-significant (M15). Thus, H6 was confirmed only when investigating short-term effects of violent behavior on union dissolution. In terms of gender differences, the $z$ statistic revealed no significant difference between males and females.

The influences of individual and background characteristics in these models were similar to the ones described in the overall offending models. The only exception is observed 
in M9 for the variable family size: males from larger families were less likely to be involved in any type of intimate relationship.

Table 3 about here

\section{DISCUSSION}

The aim of this study was to investigate the influence of past and current criminal behavior on union formation and union dissolution processes among contemporaneous Dutch young adults. Using a sample of high-risk males and females, criminal and relational careers were observed from adolescence to adulthood (up to 36 years of age). To control for selection bias, our study included a set of individual and background factors considered to be related to both offending and romantic experiences.

Our results showed that, for both males and females, past offending was associated with a lower probability of being involved in a romantic relationship (any or a living-together relationship). These results confirm findings from previous studies (van Schellen, Poortman, and Nieuwbeerta 2011; Huebner 2007; Sampson, Laub, and Wimer 2006) that stressed the long-term effects of offending on union formation. These results are consistent with the labeling framework as the theory assumes that an individual labeled as a criminal will be more likely to develop a criminal life-style, with negative consequences for romantic relationships, cumulated and perpetuated in time. Unlike previous incarceration studies, our study did not find negative short-term negative effects of offending on union formation. This difference might be explained by the fact that incarceration not only generates a criminal label but leads to acute and absolute barriers to meet (existing or potential) partners, whereas this is not the case of offending itself.

To better understand the influence of criminal behavior on intimate relationships, we also investigated the impact of two categories of serious offenses: violent and property offenses. Although only marginally significant, current violent offending was associated with a lower probability to remain single for males. One explanation for this may be that violent males have certain personality characteristics, such as being extravert, that make them attractive on the mating market (regardless of whether potential girlfriends are aware of their violent behavior). Nonetheless, the effect was not significant when living-together relationships were analyzed. Focusing on long-term effects among men, past violent offending was associated with a lower probability to be involved in a relationship (any or a 
living-together relationship). In additional analyses (results not presented), we distinguished between violent offenses in the recent past (last five years) and in the distant past (more than five years ago), and found that both recent and distant violent offenses decreased the likelihood of being involved in a relationship, suggesting that the stigma attached to violent offending does not wear off with time. At the same time, violent offending (current or past) was unrelated to involvement in romantic relationships for females. A first explanation for this is a methodological one: women committed far fewer violent offenses than men, and the sample size may have been too small to pick up any effects. Another explanation hints at differences in physical strength between men and women: because men are on average stronger than women, violent offending may signal the risk of domestic violence to women, but not to men. However, this difference between males and females should be interpreted with caution as our analysis showed no statistical difference in the effect size between males and females. The analysis of property offending provided only a single significant effect: for females, a cumulated history of property offending showed a higher probability to remain single. From our data, it is hard to clarify why women who commit property offenses have greater chances to remain single. One explanation may be that these women were hard drug addicts and stole to finance their habit, and as addicts they were less attractive partners. Further study is necessary to uncover this. Regardless of the outcome of such further study, it is remarkable that men's relational prospects are affected only once they have committed violent offenses, while for women property offenses impact their chances on the relationship market. Men, in that way, appear to have more leeway in offending: only when they cross a higher threshold of offending seriousness are their relationship prospects affected.

Our study also examined the effects of criminal behavior on union dissolution. Analyses showed that men's offending did not increase their risk of union dissolution. This result is in contrast with previous studies that focused on the effects of incarceration on separation (Western and McLanahan 2000; Lopoo and Western 2005; Apel et al. 2010). However, this is not necessarily an inconsistency as offending in our sample hardly ever entailed physical separation through detention ${ }^{3}$ with its ensuing emotional and financial stress. In contrast to the findings for males, for females current offending did increase the probability of separation. However, it should be noted that it was not possible to disentangle the temporal

\footnotetext{
${ }^{3}$ The study of criminal offending (and not incarceration) is of particular interest for The Netherlands, known for its liberal penal climate. For this reason, incarceration periods for our respondents were not considered since, in most cases, registrations would be short (limited to days and maybe weeks). We also have no indication that incarceration would bias the relationships investigated as other analyses on this sample revealed no association between incarceration, crime, and family-life events.
} 
order of current offending and union dissolution in our analysis. Thus, we cannot conclude whether offending leads to separation and divorce, or whether conflicts trigger offending.

The association between violent and property offending on the one hand, and union dissolution on the other hand was analyzed as well. Only for males, current violent offending was associated with a higher risk of separation/divorce. However, an additional statistical test showed that the coefficients did not differ significantly between males and females. Property offending had no significant influence on union dissolution for either males or females. Again, we may speculate that men who offended violently possibly also exhibited violent behavior at home. However, against this explanation speaks the fact that we did not find an effect for living-together relationships.

Overall, several findings stand out. An accumulation of past offenses reduces the likelihood of having an intimate partner for both men and women, and current offending is associated with a higher likelihood of separation for women. Furthermore, men are less likely to find a romantic partner when committing violent offenses, whereas females diminish their chances to a romantic life by engaging in property offenses. These results show firstly that an extensive criminal career jeopardizes both men's and women's chances on the relationship market. Secondly, they suggest a greater social tolerance of prospective and current partners towards crime committed by males than by females. Females seem to be labeled as deviant and suffer the negative consequences of that label when they commit relatively mild offenses (such as property offenses), whereas for males disadvantages in romantic life materialize only once they commit more severe offenses (such as violent ones).

Several theoretical perspectives argue that the effect of criminal behavior on romantic relationships might be spurious. Gottfredson and Hirschi (1990) suggest that underlying characteristics that originated in childhood (such as low self-control) account for both the involvement in criminal behavior and the reduced likelihood of forming and maintaining stable unions. To account for selection bias, our analysis included an extensive set of individual, family background and demographic predictors most likely to act as confounders in the relationship investigated. Regardless of age, ethnicity, family background (family size and divorced parents), level of education, intelligence, social skills, addiction to drugs and the age of first sexual experience, the effects described within our study remained significant.

This study increased our knowledge about the effects of criminal offending on romantic relationships. Nonetheless, several limitations have been encountered. First, the small number of married respondents did not allow for the comparison of marital and nonmarital unions. Although in the Netherlands cohabitation has become a normative experience, 
and the most common form of intimate relationship among the age groups our high-risk respondents are in, it could still be that the effects of criminal behavior on union formation/dissolution will be different for married and cohabiting individuals. Second, we were not able to distinguish between violent offending in general and violent offending targeted towards an intimate partner. This limited our interpretation of the mechanisms underlying the observed effects of violent offending on romantic relationships. Future studies should try to include a specific measure for domestic violence. Third, the current study did not include a measure of the quality of intimate relationships. Although in additional analyses (results not presented), the observed effects remained significant even after controlling for the length of the relationship (considered as a proxy for the quality of the relationship), future studies should include measures of relationship intentions and quality. Fourth, as our analysis focused on a sample of high-risk individuals, it remains difficult to generalize conclusions of this study to general population samples. Our conclusions hold for individuals with an early onset of offending, or showing serious behavioral problems in youth. Thus, replication of our findings on general population samples is needed. Fifth, given that our analysis relied on official registrations for criminal behavior, it might have underestimated the total number of crimes committed. Future research should try to combine official registration data and selfreport data to provide a better measure of criminal behavior. Also, as we relied on prosecution and conviction data, we cannot be sure whether the effects we picked up are effects of the criminal behavior as such, or of the sanctions of the criminal justice system. 


\section{REFERENCES}

Apel, R., A. Blokland, A. J., Nieuwbeerta, P., \& van Schellen, M. (2010). The impact of imprisonment on marriage and divorce: A risk set matching approach. Journal of Quantitative Criminology, 26(2), 269-300.

Barnes, J. C., Golden, K., Mancini, C., Boutwell, B. B., Beaver, K., \& Diamond, B. (2011). Marriage and involvement in crime: A consideration of reciprocal effects in a nationally representative sample. Justice Quarterly, DOI:10.1080/07418825.2011.641577,1-28.

Becker, G. S. (1973). A theory of marriage: Part I. Journal of Political Economy, 81(4), 813846.

Becker, G. S. (1993). A treatise on the family. MA: Harvard University, Cambridge.

Bersani, B., Laub, J., \& Nieuwbeerta, P. (2009). Marriage and desistance from crime in the Netherlands: Do gender and socio-historical context matter?. Journal of Quantitative Criminology, 25(1), 3-24.

Bijleveld, C.C.J.H., van der Geest, V.R. \& Hendriks, J. (2012). Vulnerable youth on pathways to adulthood. In Loeber, R., Hoeve, M., Slot, N.W. \& van der Laan, P. (eds.), Persisters and desisters in crime from adolescence into adulthood: Explanation, prevention and punishment. (pp. 105-126). Farnham: Ashgate Publishing.

Brame, R., Paternoster, R., Mazerolle, P., \& Piquero, A. (1998). Testing for the equality of maximum-likelihood regression coefficients between two independent equations. Journal of Quantitative Criminology, 14(3): 245-269.

Buikhuisen, W, \& Dijksterhuis, P. F. (1971). Delinquency and stigmatisation. British Journal of Criminology, 11(2), 185-187.

Burt, S. A., Donnellan, M. B., Humbad, M. N., Hicks, B. M., McGue, M., \& Iacono, W. G. (2010). Does marriage inhibit antisocial behavior: An examination of selection versus causation via a longitudinal twin design. Archives of General Psychiatry, 67: 1309-1315.

Centraal Bureau voor de Statistiek (2011). www.cbs.nl.

Curran, D. J., \& Renzetti, C. M. (2001). Theories of crime (2d ed.). Needham Heights, MA: Allyn and Bacon.

Cherlin, A.J. (2004). The deinstitutionalization of American marriage. Journal of Marriage and Family, 66(4), 848-861.

Edin, K., \& Kefalas, M. (2005). Promises I can keep. Why poor women put motherhood before marriage. Edited by B. U. o. C. Press 
Elzinga, C. H., \& Liefbroer, A. C. (2007). De-standardization of family-life trajectories of young adults: A cross-national comparison using sequence analysis. European Journal of Population-Revue Europeenne De Demographie, 23(3-4), 225-250.

Farrington, D. P., \& West, D. J. (1995). Effects of marriage, separation, and children on offending by adult males. In J. Hagan (ed.) Current perspectives on aging and the life cycle, Vol 4: Delinquency and disrepute in the life course. Greenwich, CT: JAI Press.

Giordano, P. C., Cernkovich, S. A., \& Rudolph, J. L. (2002). Gender, crime, and desistance: Toward a theory of cognitive transformation. American Journal of Sociology, 107(4), 9901064.

Goldscheider, F. K., \& Waite, L. J. (1986). Sex-differences in the entry into marriage. American Journal of Sociology, 92(1), 91-109.

Gottfredson, M. R., \& Hirschi, T. (1990). A general theory of crime. Stanford, Calif: Stanford University Press.

Hiekel, N. (2014). The different meanings of cohabitation across Europe. How cohabiters view their unions and differ in their plans and behaviors. Amsterdam: Amsterdam University Press.

Horney, J., Osgood, D. W., \& Marshall, I. H. (1995). Criminal careers in the short-term: Intraindividual variability in crime and its relation to local life circumstances. American Sociological Review, 60(5), 655-673.

Huebner, B. M. (2005). The effect of incarceration on marriage and work over the life course. Justice Quarterly, 22(3), 281-303.

Huebner, B. M. (2007). Racial and ethnic differences in the likelihood of marriage: The effect of incarceration. Justice Quarterly, 24(1), 156-183.

Jaffee, S. R., Lombardi, C. M., \& Coley, R. L. (2013). Using complementary methods to test whether marriage limits men's antisocial behavior. Development and Psychopathology, 25: 65-77. DOI:10.1017/S0954579412000909.

Kiernan, K. (2004). Redrawing the boundaries of marriage. Journal of Marriage and the Family, 66(4), 980-987.

King, R. D., Massoglia, M., \& MacMillan, R. (2007). The context of marriage and crime: Gender, the propensity to marry, and offending in early adulthood. Criminology, 45(1), 3365.

King, R. D., \& South, S. J. (2011). Crime, race, and the transition to marriage. Journal of Family Issues, 32(1), 99-126. 
Lemert, E. (1967). Human deviance, social problems and social control. Englewood Cliffs, NJ: Prentice-Hall.

Lonardo, R. A., Manning, W. D., Giordano, P. C. \& Longmore, M. A. (2010). Offending, substance use, and cohabitation in young adulthood. Sociological Forum, 25(4), 787-803.

London, A. S., \& Parker, W. M. (2009). Incarceration and living arrangements findings from the national health and social life survey. Journal of Family Issues, 30(6), 787-812.

Lopoo, L. M., \& Western, B. (2005). Incarceration and the formation and stability of marital unions. Journal of Marriage and Family, 67(3), 721-734.

Manting, D. (1996). The changing meaning of cohabitation and marriage. European Sociological Review, 12(1), 53-65.

Moffitt, T. E., Caspi, A., Rutter, M., \& Silva, P. A. (2001). Sex differences in antisocial behaviour: Conduct disorder, delinquency, and violence in the Dunedin Longitudinal Study. Cambridge, UK: Cambridge University Press.

Pager, D. (2003). The mark of a criminal record. American Journal of Sociology, 108(5), 937975.

Pajer, K. A. (1998). What happens to "bad" girls? A review of the adult outcomes of antisocial adolescent girls. American Journal of Psychiatry, 155(7), 862-870.

Paternoster, R., \& Iovanni, L. (1989). The labeling perspective and delinquency: An elaboration of the theory and an assessment of the evidence. Justice Quarterly, 6(3), 359394.

Rabe-Hesketh, S., \& Skrondal, A. (2008). Multilevel and longitudinal modelling using stata (2nd ed.) College Station, Texas: Stata Press.

Rebellon, C. J., \& Manasse, M. (2004). Do "bad boys" really get the girls? Delinquency as a cause and consequence of dating behavior among adolescents. Justice Quarterly, 21(2), 355-389.

Roberts, J., and Horney, J. (2010). The life event calendar method in criminological research. In Piquero, A.R., \& D. Weisburd (Eds.) Handbook of Quantitative Criminology, New York: Springer, 289-312.

Sampson, Robert J., \& Laub, J. H. (1993). Crime in the making: pathways and turning points through life. Cambridge, Mass.; London: Harvard University Press.

Sampson, R. J., Laub, J. H., \& Wimer, C. (2006). Does marriage reduce crime? A counterfactual approach to within-individual causal effects. Criminology, 44(3), 465-508.

Silverman, J. G., Raj, A., Mucci, L. A., \& Hathaway, J. E. (2001). Dating violence against adolescent girls and associated substance use, unhealthy weight control, sexual risk 
behavior, pregnancy, and suicidality. Jama-Journal of the American Medical Association, 286(5), $572-579$.

Spence, S. H. (2011). Differences in social skills performance between institutionalized juvenile male offenders and a comparable group of boys without offence records. British Journal of Clinical Psychology, 20(3), 163-171.

Tjaden, P., \& Thoennes, N. (2000). Prevalence and consequences of male-to-female and female-to-male intimate partner violence as measured by the National Violence Against Women Survey. Violence Against Women, 6(2), 142-161.

van der Geest, V., Blokland, A., \& Bijleveld, C. (2009). Delinquent development in a sample of high-risk youth: shape, content, and predictors of delinquent trajectories from age 12 to 32. Journal of Research in Crime and Delinquency, 46(2), 111-143.

van Schellen, M., Poortman, A., \& Nieuwbeerta, P. (2011). Partners in crime? Criminal offending, marriage formation, and partner selection. Journal of Research in Crime and Delinquency, 49(4), 545-571.

Western, B., \& McLanahan, S. (2000). Fathers behind bars: the impact of incarceration on family formation. In Fox, G. L., Benson, M. L., (Eds.) Families, crime and criminal justice: contemporary perspectives in family research, vol 2, Elsevier Science, New York.

Western, B., Lopoo, L. M. \& McLanahan, S. (2004). Incarceration and the bonds between parents in fragile families. In Parillo, M., Weiman, D. F., \& Western, B., (Eds.) Imprisoning America: The social effects of mass incarceration. New York: Russell Sage Foundation.

Western, B. (2006). Punishment and inequality in America. Russell Sage Foundation, New York.

Zoutewelle-Terovan, M., van der Geest, V., Liefbroer, A. C., \& Bijleveld, C. (2012). Criminality and family formation: Effects of marriage and parenthood on criminal behavior for men and women. Crime and Delinquency, DOI: 10.1177/0011128712441745, $1-26$. 
FIGURES AND TABLES

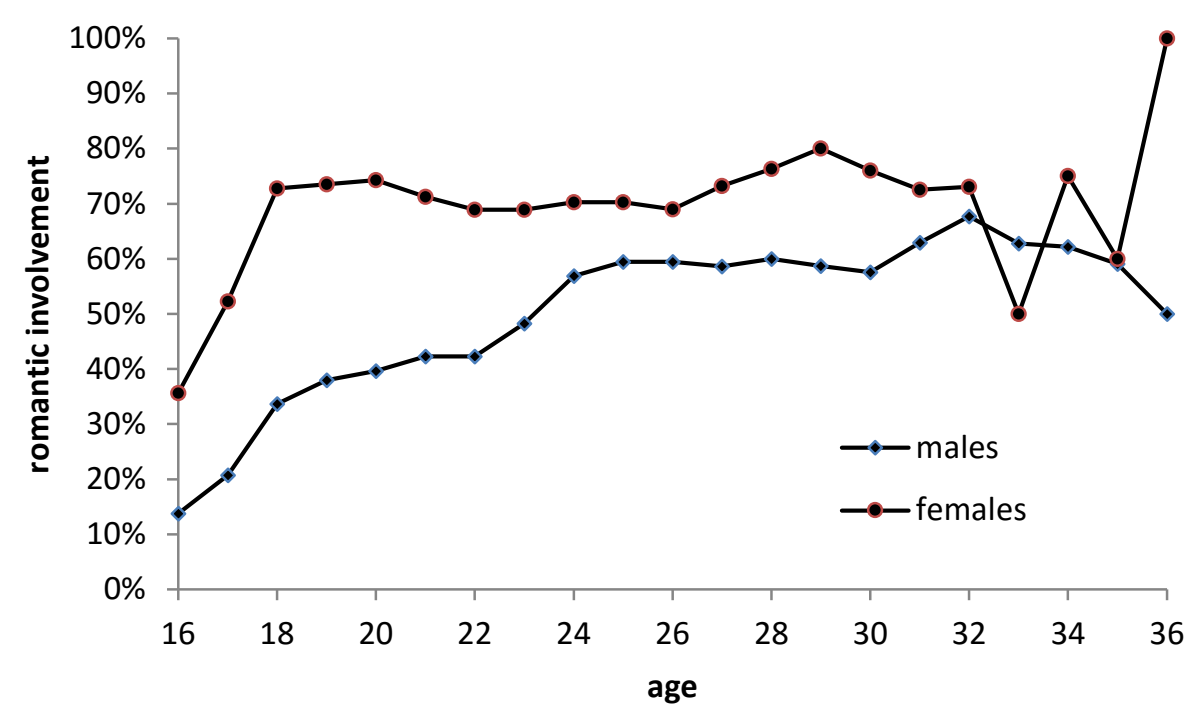

Figure 1. Percentage of men and women romantically involved, by age

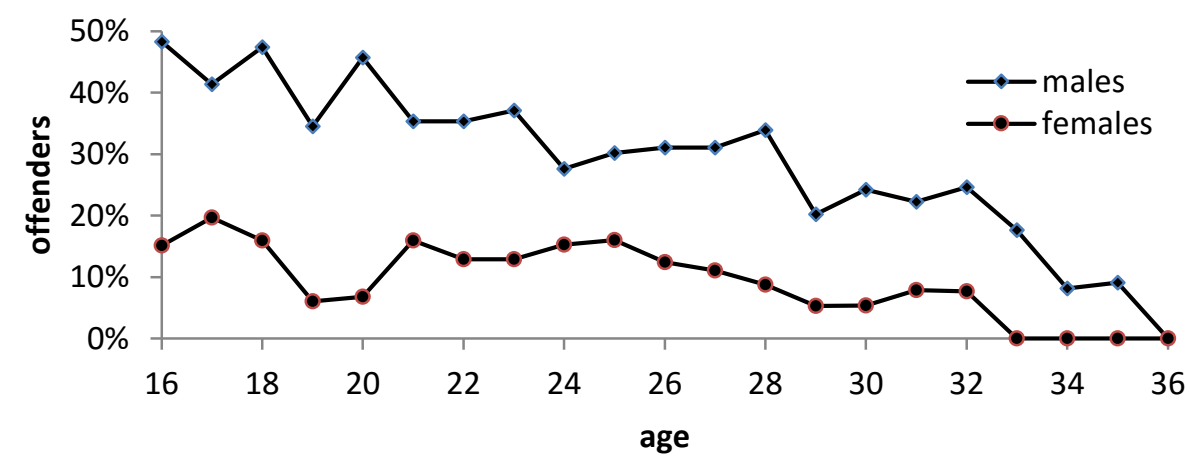

Figure 2. Percentage of men and women committing at least one offence, by age

Table 1. Descriptive information regarding individual characteristics

\begin{tabular}{lll}
\hline Variables & Males & Females \\
\hline Dutch ethnicity & $60.3 \%$ & $69.7 \%$ \\
Family size (average) & 3.7 & 4.2 \\
Parental divorce & $61.2 \%$ & $66.7 \%$ \\
Low educational level & $30.2 \%$ & $25.0 \%$ \\
IQ & $24.1 \%$ below average & $34.1 \%$ below average \\
Insufficient social skills & $68.1 \%$ & $82.6 \%$ \\
Addiction to drugs & $31.9 \%$ & $14.4 \%$ \\
Age of first sexual experience (average) & 15.1 & 15.2 \\
\hline
\end{tabular}


Table 2. Effects (relative risk ratios) of offending on romantic relationships

\begin{tabular}{|c|c|c|c|c|c|c|c|c|}
\hline \multirow{3}{*}{ VARIABLES } & \multicolumn{4}{|c|}{ having a relationship } & \multicolumn{4}{|c|}{ Separation } \\
\hline & \multicolumn{2}{|c|}{$\begin{array}{c}\text { any } \\
\text { relationship }\end{array}$} & \multicolumn{2}{|c|}{$\begin{array}{l}\text { living-together } \\
\text { relationship }\end{array}$} & \multicolumn{2}{|c|}{$\begin{array}{c}\text { any } \\
\text { relationship }\end{array}$} & \multicolumn{2}{|c|}{$\begin{array}{l}\text { living-together } \\
\text { relationship }\end{array}$} \\
\hline & Males & Females & Males & Females & Males & Females & Males & Females \\
\hline Model & M1 & M2 & M3 & M4 & M5 & M6 & M7 & M8 \\
\hline Age & $2.19 * * *$ & $2.16^{* * *}$ & $3.35 * * *$ & $2.80 * * *$ & 1.26 & 1.37 & 1.19 & 1.07 \\
\hline $\mathrm{Age}^{2}$ & $0.99 * * *$ & $0.99 * * *$ & $0.98 * * *$ & $0.98 * * *$ & 0.99 & 0.99 & 1.00 & 1.00 \\
\hline Current offending & 1.02 & 0.93 & 1.03 & 0.92 & 1.05 & $1.21 *$ & 1.07 & $1.37 * *$ \\
\hline Past offending & $0.97 *$ & $0.89 * * *$ & $0.96 *$ & $0.93^{*}$ & 1.03 & 1.01 & 1.03 & 0.97 \\
\hline Dutch ethnicity & 0.77 & 1.03 & 0.93 & 2.03 & 0.70 & 1.00 & 0.98 & 0.95 \\
\hline Family size & 0.85 & $1.24 *$ & 0.91 & 1.21 & 0.90 & 0.91 & 1.04 & $0.87 *$ \\
\hline Parental divorce & 1.32 & 1.65 & 0.85 & 1.53 & 1.18 & 0.82 & 1.04 & 0.94 \\
\hline Level of education & 1.05 & 1.15 & 1.29 & 0.98 & 0.65 & 0.89 & 1.14 & 1.10 \\
\hline IQ & 1.22 & 1.01 & 1.11 & 1.10 & 0.88 & 1.10 & 0.84 & 1.18 \\
\hline Insufficient social skills & 1.19 & 1.89 & 0.95 & 1.17 & 0.78 & $0.63 *$ & 0.87 & 0.63 \\
\hline Drug addiction & 1.30 & 0.65 & 1.56 & 1.08 & 0.55 & $1.64 *$ & 0.85 & 1.63 \\
\hline Age first sex & 1.06 & $0.86^{*}$ & 0.96 & $0.83^{*}$ & 1.03 & 1.02 & 0.97 & 0.99 \\
\hline$N$ & 116 & 132 & 116 & 132 & 112 & 129 & 104 & 115 \\
\hline
\end{tabular}


Table 3. Effects (relative risk ratios) of violent and property offending on romantic relationships

\begin{tabular}{|c|c|c|c|c|c|c|c|c|}
\hline \multirow{3}{*}{ VARIABLES } & \multicolumn{4}{|c|}{ having a relationship } & \multicolumn{4}{|c|}{ Separation } \\
\hline & \multicolumn{2}{|c|}{$\begin{array}{c}\text { any } \\
\text { relationship }\end{array}$} & \multicolumn{2}{|c|}{$\begin{array}{l}\text { living-together } \\
\text { relationship }\end{array}$} & \multicolumn{2}{|c|}{$\begin{array}{c}\text { any } \\
\text { relationship }\end{array}$} & \multicolumn{2}{|c|}{$\begin{array}{l}\text { living-together } \\
\text { relationship }\end{array}$} \\
\hline & Males & Females & Males & Females & Males & Females & Males & Females \\
\hline Model & M9 & M10 & M11 & M12 & M13 & M14 & M15 & M16 \\
\hline Age & $2.25 * * *$ & $2.14 * * *$ & $3.40 * * *$ & $2.78 * * *$ & 1.28 & 1.38 & 1.21 & 1.07 \\
\hline $\mathrm{Age}^{2}$ & $0.99 * * *$ & $0.99 * * *$ & $0.98 * * *$ & $0.98 * * *$ & 0.99 & 0.99 & 1.00 & 1.00 \\
\hline Current violent & $1.28 *$ & 0.85 & 1.24 & 1.15 & $1.46^{*}$ & 1.20 & 1.42 & 1.21 \\
\hline Past violent & $0.84 * *$ & 1.08 & $0.85^{*}$ & 0.97 & 1.11 & 1.10 & 1.06 & 1.34 \\
\hline Current property & 0.94 & 1.06 & 0.97 & 0.91 & 1.04 & 1.12 & 1.08 & 1.26 \\
\hline Past property & 0.98 & $0.86^{* *}$ & 0.97 & 0.95 & 1.02 & 1.03 & 1.03 & 0.94 \\
\hline Dutch ethnicity & 0.75 & 1.09 & 0.91 & 2.11 & 0.71 & 1.00 & 0.99 & 0.95 \\
\hline Family size & $0.84 *$ & $1.23 *$ & 0.90 & 1.21 & 0.91 & 0.91 & 1.05 & $0.87 *$ \\
\hline Parental divorce & 1.35 & 1.62 & 0.87 & 1.52 & 1.21 & 0.83 & 1.04 & 0.92 \\
\hline Level of education & 1.03 & 1.16 & 1.27 & 0.98 & 0.64 & 0.89 & 1.12 & 1.10 \\
\hline IQ & 1.20 & 1.02 & 1.09 & 1.10 & 0.91 & 1.10 & 0.87 & 1.18 \\
\hline Insufficient social skills & 1.21 & 1.78 & 0.97 & 1.11 & 0.73 & $0.64 *$ & 0.84 & 0.63 \\
\hline Drug addiction & 1.29 & 0.58 & 1.55 & 0.98 & 0.61 & $1.63 *$ & 0.88 & 1.56 \\
\hline Age first sex & 1.06 & $0.87 *$ & 0.96 & $0.83 *$ & 1.05 & 1.02 & 0.98 & 0.99 \\
\hline$N$ & 116 & 132 & 116 & 132 & 112 & 129 & 104 & 115 \\
\hline
\end{tabular}

